\title{
Characterization of cholesterol oxidase from Streptomyces hygroscopicus and Brevibacterium sterolicum
} \author{
Mirella S. PILONE ${ }^{1}$ and Sandro GHISLA ${ }^{2}$ \\ 1 Department of Structural and Functional Biology, University of Milano, Varese, Italy \\ 2 Faculty of Biology, University of Konstanz, Konstanz, Germany \\ 3 Boehringer Mannheim GmbH, Biotechnology Research Center, Penzberg, Germany
}

Giovanni GADDA ${ }^{1}$, Gaby WELS ${ }^{2}$, Loredano POLLEGIONI ${ }^{1}$, Silvia ZUCCHELLI ${ }^{1}$, Dorothea AMBROSIUS ${ }^{3}$,

The FAD-containing enzyme cholesterol oxidase catalyzes the oxidation and isomerization of $3 \beta$ hydroxysteroids having a trans double bond at $\Delta^{5}-\Delta^{6}$ of the steroid ring backbone to the corresponding $\Delta^{4}$ 3-ketosteroid. Two representative enzymes of this family, namely cholesterol oxidase from Streptomyces hygroscopicus (SCO) and the recombinant enzyme from Brevibacterium sterolicum (BCO) expressed in Escherichia coli, have been characterized herein in their chemical, physical, and biochemical properties. In the native form, both enzymes are monomeric $(55 \mathrm{kDa})$, acidic (pI 4.4-5.1) and contain oxidized FAD (peaks in the 370-390-nm and 440-470-nm regions). Marked differences exist between the oxidized, reduced, and (red) anion semiquinone spectra of the two enzymes, suggesting substantial differences in the flavin microenvironment. Both enzymes form reversibly flavin $N(5)$-sulfite adducts via measurable $k_{\text {on }}$ and $k_{\text {off }}$ steps. BCO has a higher affinity for sulfite $\left(K_{\mathrm{d}} \approx 0.14 \mathrm{mM}\right)$ compared to SCO $(\approx 24 \mathrm{mM})$. This correlates well with the midpoint redox potentials of the bound flavin, which in the case of BCO are about $100 \mathrm{mV}$ more positive than for SCO. Both enzymes show a high $\mathrm{p} K_{\mathrm{a}}(\approx 11.0)$ for the $\mathrm{N}(3)$ position of FAD. With both enzymes, the rearrangement of 5-cholesten-3-one to 4-cholesten-3-one is not rate limiting indicating that the rate-limiting step of the overall reaction is not the isomerization. The absence of the double bond in the steroid molecule does not significantly affect turnover and affinity for the substrate, whereas both these parameters are affected by a decreasing length of the substrate C17 chain.

Keywords: cholesterol oxidase; flavoenzyme; catalytic property; redox potential.

Cholesterol oxidase (CO) is a FAD-dependent enzyme that catalyzes the oxidation and isomerization of $3 \beta$-hydroxysteroids having a trans double bond at $\Delta^{5}-\Delta^{6}$ of the steroid ring yielding the corresponding $\Delta^{4}$-3-ketosteroid and hydrogen peroxide (see Scheme 1). Although the enzyme works on a broad range of steroid substrates, the 3-hydroxy group in the position of the sterol molecule is an absolute substrate requirement for the oxidation reaction (Smith and Brooks, 1975; Kamei et al., 1978; Inouye et al., 1982). The enzyme has been isolated from several sources, including member of the genera Streptomyces (Kamei et al., 1978), Brevibacterium (Uwajima et al., 1973), Pseudomonas (Lee et al., 1989), Schizophyllum (Fukuyama and Miyake, 1979), and Rhodococcus (Johnson and Somkuti, 1991). CO from bacterial sources exhibits a wide range of clinical and industrial applications, as it is used in the clinical determination of choles-

Correspondence to M. S. Pilone, Department of Structural and Functional Biology, University of Milano, via Ravasi 2, I-21100 Varese, Italy Fax: +332281308

E-mail: mir@imiucca.csi.unimi.it

URL: http//imiucca.cca.csi.unimi.it/ biolib/dbsf.html

Abbreviations. SCO, cholesterol oxidase from Streptomyces hygroscopicus; $\mathrm{BCO}$, recombinant cholesterol oxidase from Brevibacterium sterolicum expressed in Escherichia coli; cholesterol, 5-cholestene-3 $\beta$ ol; trans-dehydroandrosterone, 5 -androstene- $3 \beta$-ol-17-one; pregnenolone, 5-pregnene-3 $\beta$-ol-20-one; trans-androsterone, $5 \alpha$-androstan- $3 \beta$-ol17-one; cholestanol, $5 \alpha$-cholestan- $3 \beta$-ol.

Enzyme. Cholesterol oxidase (EC 1.1.3.6). terol concentration for the assessment of arteriosclerosis and other lipid disorders, in the microanalysis of steroids in food specimens, for the determination of the steric configuration of $3 \beta$-hydroxysteroids and in the preparation of 3-ketosteroids from their corresponding $3 \beta$-hydroxysteroids. In addition, $\mathrm{CO}$ from Streptomyces (strain A19249) exhibits a potent insecticidal activity (Purcell et al., 1993; Corbin et al., 1994; Ghoshroy et al., 1997).

In spite of this broad spectrum of applications and interests, and the fact that the three-dimensional structure of $\mathrm{CO}$ from Brevibacterium sterolicum (American Type Culture Collection no. 21387) in the presence and in the absence of a steroid substrate has become available (Vrielink et al., 1991; Li et al., 1993), a thorough chemical, physical, and biochemical characterization of this group of enzymes has not yet been reported. On the other hand, there is a wealth of literature dealing with some detailed aspects of particular CO enzymes. We have thus carried out a study of two representative enzymes of this family, namely cholesterol oxidase from Streptomyces hygroscopicus (SCO) and the recombinant enzyme from Brevibacterium sterolicum (BCO) expressed in E. coli. SCO is largely used in biotechnological applications, and $\mathrm{BCO}$ is of particular interest since it originates from a $B$. sterolicum strain. This microorganism is also the biological source of the $\mathrm{CO}$ from which the three-dimensional structure has been determined in Blow's group (Vrielink et al., 1991). The latter contains non-covalently bound FAD, while the BCO studied in this work contains FAD 
covalently linked to a histidine of the peptide backbone. The elucidation of its three-dimensional structure is in progress (Croteau and Vrielink, 1996). A detailed comparison of the two CO enzymes, which have similar properties, might elucidate whether, at least in the present case, covalent flavin linkage to the protein is merely due to the 'accidental presence' of a histidine in its vicinity, or has a still unrecognized function.

\section{MATERIALS AND METHODS}

Materials and enzymes. 5-Cholestene-3 $\beta$-ol (cholesterol), 5 -androstene-3 $\beta$-ol-17-one (trans-dehydroandrosterone), 5-pregnene- $3 \beta$-ol-20-one (pregnenolone), $5 \alpha$-cholestan- $3 \beta$-ol (cholestanol), Thesit, and Triton X-100 were purchased from Boehringer Mannheim; EDTA and SDS were from Sigma; isopropanol and sodium sulfite were from Merck. All other reagents were of the highest purity commercially available. SCO, purified from S. hygroscopicus cells (Wels, 1997), and recombinant B. sterolicum CO (Jarsch, M., patent no. DE 4342012 A1, 1994), expressed and purified from $E$. coli cells, were obtained from Boehringer.

Enzymatic activity. Cholesterol oxidase activity was assayed using the following methods: polarographically $\left(\left[\Delta \mathrm{O}_{2}\right]\right.$ assuming $\left[\mathrm{O}_{2}\right]=0.253 \mathrm{mM}$ at $25^{\circ} \mathrm{C}$ in air); spectrophotometrically (production of 4-cholesten-3-one followed at $240 \mathrm{~nm}$, assuming $\varepsilon_{240}=15500 \mathrm{M}^{-1} \mathrm{~cm}^{-1}$ ); via determination of $\mathrm{H}_{2} \mathrm{O}_{2}$ with an enzyme-coupled assay using horseradish peroxidase (Macheroux et al., 1991) $(0.01 \mathrm{mg} / \mathrm{ml})$ and $o$-dianisidine $(0.16 \mathrm{mg} / \mathrm{ml})$ followed at $440 \mathrm{~nm}$, assuming $\varepsilon_{440}=13000 \mathrm{M}^{-1}$ $\mathrm{cm}^{-1}$ at $25^{\circ} \mathrm{C}$ in $0.5 \mathrm{M}$ potassium phosphate, $\mathrm{pH}$ 7.5. The presence of a detergent (Thesit) and of an alcohol (isopropanol) is required for the optimal solubilization of the substrates. With trans-dehydroandrosterone and pregnenolone, the production of 4-androstene-3,17-dione and 4-pregnene-3,20-dione was followed at $240 \mathrm{~nm}$, assuming $\varepsilon_{240}=16200 \mathrm{M}^{-1} \mathrm{~cm}^{-1}$ and $\varepsilon_{240}=$ $17100 \mathrm{M}^{-1} \mathrm{~cm}^{-1}$, respectively.

Absorption and fluorescence measurements. Absorption spectra were recorded with a Uvikon 860 or 930 spectrophotometer (Kontron Instruments). Excitation and emission spectra with a Jasco FP-777 or Kontron SFM 25 spectrofluorometer. Unless otherwise stated, all spectra were recorded in $0.1 \mathrm{M}$ potassium phosphate, $\mathrm{pH} 7.5$, and $25^{\circ} \mathrm{C}$. The spectra of the semiquinone and fully reduced forms of both $\mathrm{CO}$ enzymes were obtained by deconvolution analysis of the spectrophotometric data using the program Specfit (Spectrum Software Assoc., Chapel Hill, NC). The spectra were recorded during the process of anaerobic reduction in the presence of benzyl viologen and of the xanthine/ xanthine oxidase as detailed below.

Flavin content and absorption coefficients. Flavin was extracted from SCO by heating the enzyme at $95^{\circ} \mathrm{C}$ for $3 \mathrm{~min}$ and removing denatured protein by centrifugation. The flavin in the supernatant was identified by its absorption spectrum compared to that of native FAD, and by fluorescence spectroscopy determination before and after treatment with phosphodiesterase, which generates FMN and increases the fluorescence yield eightfold (Whitby, 1953). Absorption coefficients were determined upon unfolding the protein in $0.5 \% \mathrm{SDS}$ at $25^{\circ} \mathrm{C}$ for $10 \mathrm{~min}$ in $0.1 \mathrm{M}$ potassium phosphate, $\mathrm{pH} 7.5$, and using the known $\varepsilon_{448}$ of free FAD (Whitby, 1953).

Redox potentials. The redox potentials were determined in $100 \mathrm{mM}$ potassium phosphate, $\mathrm{pH} 7.5$, at $15^{\circ} \mathrm{C}$ using the spectrophotometric method described by Massey (1991) and employing the xanthine and xanthine oxidase reducing system. Cresyl violet acetate, indigo disulfonate, indigo trisulfonate, benzyl viologen, and safranin T (all from Sigma) were used as indicator dyes.
Miscellaneous methods. For reactions with sulfite, the reagent was prepared just before use as $2 \mathrm{M}$ stock solution in $0.1 \mathrm{M}$ potassium phosphate, $\mathrm{pH}$ 7.5. Aliquots were then added to enzyme solution in $0.1 \mathrm{M}$ potassium phosphate, $\mathrm{pH} 7.5$, at $25^{\circ} \mathrm{C}$. The rate of decay $\left(k_{\text {off }}\right.$, dissociation of $\left.\mathrm{SO}_{3}^{2-}\right)$ for the $N(5)-$ sulfite adduct was determined spectrophotometrically after removing excess sulfite by gel filtration (application of 1-ml samples to a Sephadex G- 25 column, void volume $6 \mathrm{ml}$, at $4{ }^{\circ} \mathrm{C}$ ). Anaerobic experiments were performed on samples prepared by alternate evacuation and flushing with $\mathrm{O}_{2}$-free nitrogen in 1-ml cells equipped with side-arms. Photoreduction in the presence of EDTA was conducted as described by Massey et al. (1978) in $0.1 \mathrm{M}$ potassium phosphate, $\mathrm{pH} 7.5$, at $25^{\circ} \mathrm{C}$. The cuvette with the protein solution was in a water bath at $10^{\circ} \mathrm{C}$ and at approximately $7 \mathrm{~cm}$ from a $150-\mathrm{W}$ quartz halogen light source. The cuvette was removed at time intervals and absorption spectra were recorded. SDS/PAGE was performed according to Laemmli (1970). Analytical isoelectrofocusing was accomplished in a $2.5-\mathrm{mm}$-thick $7 \%$ acrylamide slab in $2.5 \%$ ampholine pharmalyte (Pharmacia) over the $\mathrm{pH}$ range $2.5-8.0$ at $10^{\circ} \mathrm{C}$. Gels were stained for protein with Coomassie brilliant blue R250 and for activity by incubating the gels for $45 \mathrm{~min}$ at $30^{\circ} \mathrm{C}$ in the following medium: $1.4 \mathrm{mM} 3 \beta$-hydroxy-5-androsten-17one and $1.4 \mathrm{mM} 5$-pregnenolone in $0.5 \mathrm{M}$ potassium phosphate, $\mathrm{pH} 7.5,1 \%$ Thesit, $1.25 \%$ isopropanol, and $0.025 \%$ iodonitrotetrazolium. Gel filtration of CO was accomplished with a Superose 12 or a Superdex 200 column using an FPLC system (Pharmacia). Columns were equilibrated with $0.1 \mathrm{M}$ potassium phosphate, $\mathrm{pH} 7.5$, with or without $0.3 \mathrm{M} \mathrm{KCl}$ and eluted at a flow rate of $0.5 \mathrm{ml} / \mathrm{min}$. Alternatively, an Ultrogel AcA 44, a Sephacryl S-200, or a Sephadex G-100 column $(1 \mathrm{~cm} \times 40 \mathrm{~cm})$ were used at a flow rate of $0.2 \mathrm{ml} / \mathrm{min}$ with an Econo-System apparatus (Bio-Rad). Molecular mass standards: $\beta$-amylase $(200 \mathrm{kDa})$, alcohol dehydrogenase $(150 \mathrm{kDa})$, albumin $(66 \mathrm{kDa})$, carbonic anhydrase $(29 \mathrm{kDa})$, and cytochrome $c(12 \mathrm{kDa})$. Determination of the aggregation state of the two proteins under native conditions was performed in the $1-100 \mu \mathrm{M}$ enzyme concentration range.

\section{RESULTS AND DISCUSSION}

Molecular mass. BCO and SCO are apparently pure as judged from SDS/PAGE and have molecular masses of $55 \mathrm{kDa}$ and $53 \mathrm{kDa}$, respectively. These values are within the range of molecular masses reported for COs from other sources (Kamei et al., 1978; Fukuyama and Miyake, 1979; Inouye et al., 1982; Ishizaki et al., 1989; Otha et al., 1991; Purcell et al., 1993). Under non-denaturing gel filtration conditions (on Superose 12 or Superdex 200 matrix) BCO yielded a single symmetrical peak corresponding to a mass of $\approx 48.0 \pm 2.0 \mathrm{kDa}$. Using the same experimental approach with SCO, however, a value between $7.5 \mathrm{kDa}$ and $32.5 \mathrm{kDa}$ was obtained using Superose 12, Superdex 200, Ultrogel AcA 44, or Sephacryl S-200 matrices. A low molecular mass under non-denaturing conditions has been reported for $\mathrm{CO}$ from Schizophyllum comune (Fukuyama and Miyake, 1979). This probably stems from interactions of the enzyme with the matrix of the agarose-based resins. An estimation of the native mass of this protein $(\approx 45 \mathrm{kDa})$, in good agreement with the SDS/PAGE value, was obtained on a Sephadex G-100 column, which has a dextran matrix. Thereby, both enzymes were monomeric in the $1-100 \mu \mathrm{M}$ protein concentration range.

On the other hand, under non-denaturing PAGE conditions BCO and SCO resolved into three and two protein bands, respectively. Similarly, isoelectrofocusing under native conditions resulted in three and two protein bands for BCO (pI 5.1, 5.0 and 


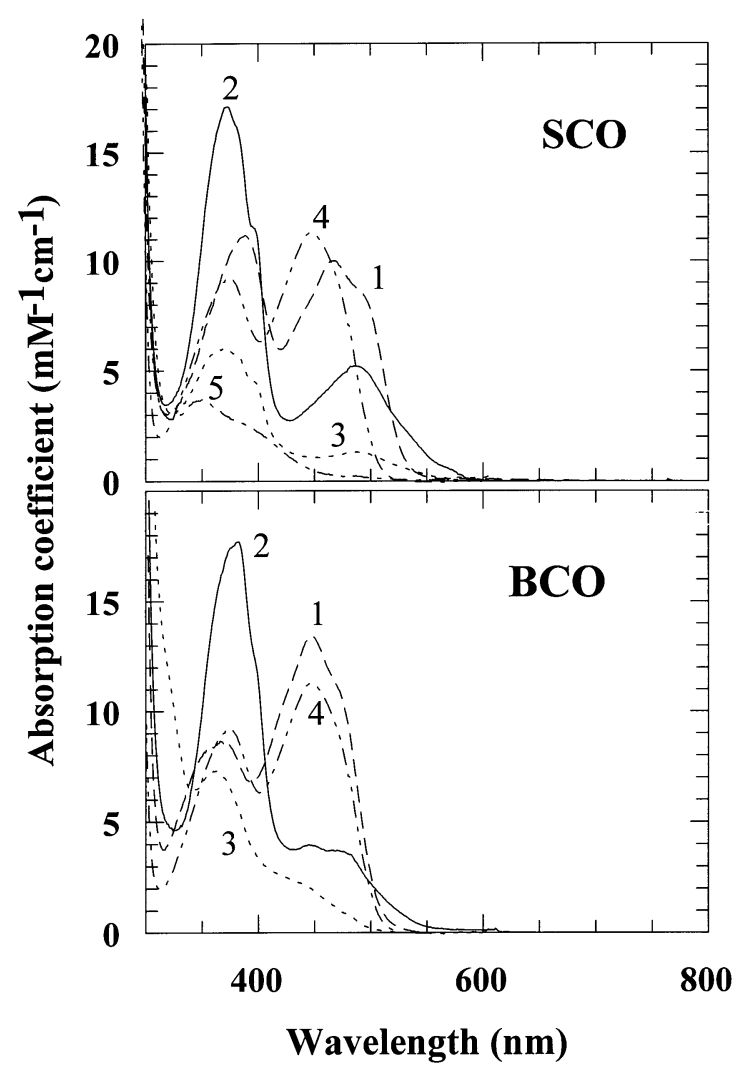

Fig. 1. Absorption spectra of $S$. hygroscopicus and B. sterolicum cholesterol oxidases in their oxidized, half-, and fully-reduced states. (1) Oxidized enzyme in $0.1 \mathrm{M}$ potassium phosphate, $\mathrm{pH} 7.5$, at $25^{\circ} \mathrm{C}$. The spectra of the semiquinone (2) and fully reduced (3) enzyme forms were derived from deconvolution analysis of series of spectra obtained during anaerobic reduction using the xanthine and xanthine oxidase system in the presence of $5 \mu \mathrm{M}$ benzyl viologen (see Materials and Methods section for details). In the case of SCO, trace (3) does not correspond to the fully reduced species, which could not be attained by this method. Full reduction of SCO was obtained upon anaerobic addition of cholesterol and the species is represented by curve (5). In the case of BCO, curve (3) is identical with that obtained upon anaerobic addition of substrate. (4) Spectra obtained upon treatment with $0.5 \%$ SDS for $5 \mathrm{~min}$ at $25^{\circ} \mathrm{C}$, corresponding to the spectra of free FAD.

4.9 ; intensity $\approx 5,35$, and $60 \%$ ) and SCO (pI 4.5 and pI 4.4; intensity $\approx 25 \%$ and $75 \%$ ), respectively. First attempts to characterize the different bands for activity on cholesterol using either diazonium salts or $o$-dianisidine were unsuccessful. Staining of activity was then achieved using $3 \beta$-hydroxy-5-androsten17 -one and pregnenolone as substrates in the presence of iodonitrotetrazolium salts. For SCO and using activity staining, two bands were detected that correspond to those obtained with protein staining ( $\mathrm{pI} 4.5$ and $\mathrm{pI} 4.4$; intensity $\approx 25 \%$ and $75 \%$, respectively) (data not shown). The molecular basis for this heterogeneity is not yet known and is under investigation. In any event, the differences did not appear to affect catalytic properties and specific properties such as ligand binding or formation of radical/fully reduced species (see below and Wels, 1997).

Spectral properties and their $\mathbf{p H}$ dependence. Both $\mathrm{SCO}$ and BCO exhibited rather unusual absorption spectra in their oxidized states as shown in Fig. 1, where the spectra are compared to that of free FAD (relevant spectral data are summarized in Table 1). The spectrum of SCO is peculiar in that the intensity ratio of the visible and of the near-ultraviolet bands is inverted
Table 1. Spectral properties of cholesterol oxidase from B. sterolicum and $S$. hygroscopicus. The enzyme solutions used for obtaining the absorbance spectra were $10 \mu \mathrm{M}$ in $0.1 \mathrm{M}$ potassium phosphate, $\mathrm{pH} 7.5$, at $25^{\circ} \mathrm{C}$, those for fluorescence spectra were $5 \mu \mathrm{M}$ in the same buffer. Semiquinone and reduced enzymes were obtained by deconvolution analysis (see Fig. 1).

\begin{tabular}{lll}
\hline Enzyme (redox state) & BCO & SCO \\
\hline $\mathrm{E}_{\text {ox }}, \lambda_{\max }(\mathrm{nm})$ & $275,368,448$ & $278,388,467$ \\
$\varepsilon\left(\mathrm{mM}^{-1} \mathrm{~cm}^{-1}\right)$ & $170,8.7,13.4$ & $132,11.1,10$ \\
$\quad$ Absorbance ratios & $12.7,0.65,1$ & $14.7,1.11,1$ \\
$\quad$ Fluorescence emission $\left(\lambda_{\max }, \mathrm{nm}\right)$ & 325,525 & 330,525 \\
$\quad\left(\lambda_{\text {exc }}=280 ; 450 \mathrm{~nm}\right)$ & & \\
$\%$ of that of free FAD & 0.5 & 0.6 \\
$\mathrm{E}_{\text {red }}, \lambda_{\max }(\mathrm{nm})$ & 268,362 & 271,370 \\
$\varepsilon\left(\mathrm{mM}^{-1} \mathrm{~cm}^{-1}\right)$ & $174.4,7.3$ & $129,6.0$ \\
$\quad$ Fluorescence emission $\left(\lambda_{\max }, \mathrm{nm}\right)$ & 325,490 & 325,490 \\
$\quad\left(\lambda_{\text {exc }}=280,340 \mathrm{~nm}\right)$ & 1.8 & 1.7 \\
$\quad \%$ of that of free FAD & 382,445 & 372,485 \\
$\mathrm{E}_{\text {semiquinone }}, \lambda_{\max }(\mathrm{nm})$ & $17.7,4.0$ & $17.1,5.2$ \\
$\varepsilon\left(\mathrm{mM}^{-1} \mathrm{~cm}^{-1}\right)$ & 329 & 329 \\
$\mathrm{E}_{\text {sulfite-adduct, }} \lambda_{\max }(\mathrm{nm})$ & 9.2 & 3.0 \\
$\varepsilon\left(\mathrm{mM}^{-1} \mathrm{~cm}^{-1}\right)$ & & \\
\hline
\end{tabular}

compared to that of free FAD, and, intriguingly, it is closely similar to that of oxynitrilase (Massey et al., 1969), an enzyme with which it shares also some features of sulfite complexation (see below). These spectra suggest that the factors affecting the visible band, i.e. the environment of the chromophore, are substantially different in SCO compared to BCO. Substantial differences are also found for the semiquinone spectra (Fig. 1), where SCO has a maximum at $485 \mathrm{~nm}$, while that of BCO shows peaks at $445 \mathrm{~nm}$ with a shoulder at $485 \mathrm{~nm}$. Similarly, the spectra of the reduced species are very different, that of SCO being rather featureless, and that of BCO resembling that of reduced flavodoxin (Ghisla et al., 1974). While a molecular interpretation of these differences will have to await the elucidation of the threedimensional structure, it appears that the factors (probably dipoles and hydrogen bridges) affecting the intensities of the bands, and in particular those of the first $\left(S_{0} \rightarrow S_{1}\right)$ transition, are drastically different. This, in turn, suggests the presence of substantial differences at the catalytic loci of BCO and SCO. No relevant spectral changes were observed upon addition of inorganic ions such as $\mathrm{Cl}^{-}, \mathrm{Br}^{-}, \mathrm{I}^{-}, \mathrm{NO}_{3}^{-}$and $\mathrm{P}_{\mathrm{i}}^{-}$at a concentration up to $0.2 \mathrm{M}$ to solutions of $\mathrm{CO}$ in $10 \mathrm{mM}$ imidazole, $\mathrm{pH} 7.0$, at $25^{\circ} \mathrm{C}$. Attempts to assess the binding of 5-cholesten-3-one (product) to both $\mathrm{CO}$ enzymes by monitoring spectral changes (differential spectroscopy) of the flavin chromophore were essentially negative. Considering the three-dimensional structure of CO from Brevibacterium (Li et al., 1993) this is not entirely surprising, since in this structure little interaction between substrates and the flavin at the active site is depicted, the 3-OH function of the former being the only part of the substrate molecule that is in contact with the flavin, namely near the $\mathrm{N}(5)$ position.

Both oxidized enzymes show a marked dependence of the absorption spectrum on $\mathrm{pH}$. With $\mathrm{BCO}$ and at high $\mathrm{pH}$ values $(>11)$, a bathochromic shift is observed for the near-ultraviolet band $(340-350 \mathrm{~nm})$. This is consistent with $\mathrm{N}(3)-\mathrm{H}$ of bound FAD being not ionized at physiological $\mathrm{pH}$. Both enzymes have $\mathrm{p} K$ values that are substantially increased $(\mathrm{BCO}: \approx 10.9 \pm 0.25$ compared to $\approx 10$ for free FAD) (Massey and Ganther, 1965). However, $\mathrm{BCO}$ undergoes denaturation at $\mathrm{pH}>12$; it is dena- 


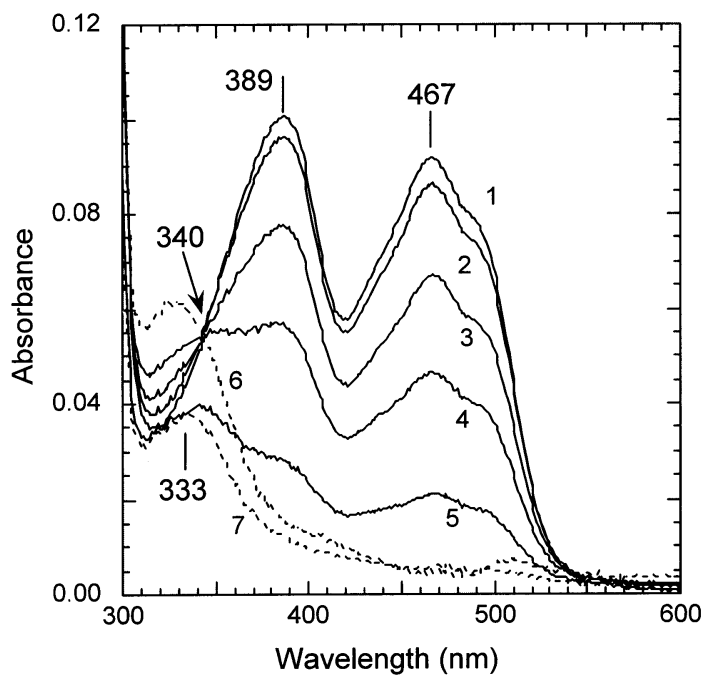

Fig. 2. Binding of sulfite to cholesterol oxidase from S. hygroscopicus. Curve (1) is that of SCO, $9.1 \mu \mathrm{M}$ in $0.1 \mathrm{M}$ potassium phosphate, $\mathrm{pH} 7.5$, at $25^{\circ} \mathrm{C}$. This solution was titrated with incremental concentrations of sulfite. Selected spectra, obtained upon addition of (2) 2, (3) 10, (4) 46, and (5) $656 \mathrm{mM}$ sulfite are shown. Curves (6) and (7) were obtained from curves 4 and 5, respectively, by subtraction of $48 \%$ and $18 \%$ oxidized enzyme (curve 1), respectively, and normalization.

Table 2. Parameters of the reaction of cholesterol oxidase with sulfite. The rates were determined spectroscopically by following the absorbance changes of the oxidized form of the enzyme at $450 \mathrm{~nm}$ and as described in the Materials and Methods section. The values of $k_{\text {on }}$ are the slopes of the linear plot of the rates at different sulfite concentrations, $k_{\text {off }}$ the abscissa intercept, and $k_{\text {off }}$ in brackets the rates determined directly upon Sephadex G25 gel filtration of preformed complex to remove excess sulfite. $K_{\mathrm{d}}$ is the result of static experiments in which the absorbance was read at $\approx 450 \mathrm{~nm}$ after spectral changes had ceased.

\begin{tabular}{lllll}
\hline Enzyme & $k_{\text {on }}$ & $k_{\text {off }}$ & $K_{\mathrm{d}}\left(=k_{\text {off }} / k_{\text {on }}\right)$ & $K_{\mathrm{d}}$ \\
\hline & $\mathrm{M}^{-1} \cdot \mathrm{min}^{-1}$ & $\min ^{-1}$ & $\mathrm{mM}$ & \\
\cline { 3 - 5 } BCO & 370 & $0.05(0.05)$ & $0.13(0.14)$ & 0.14 \\
SCO & 7 & $0.4(0.3)$ & $55(45)$ & 24 \\
\hline
\end{tabular}

tured to $\approx 5 \%$ when brought to $\mathrm{pH} 12$, and the $\mathrm{pH}$ then readjusted to 7 within $10 \mathrm{~min}$ and at $15^{\circ} \mathrm{C}$.

The fluorescence emission of both $\mathrm{CO}$ enzymes is rather weak in the oxidized states with $\lambda_{\text {max (emiss) }} \approx 525 \mathrm{~nm}$ (Table 1 ). The emission of the reduced forms is approximately threefold higher and has $\lambda_{\text {(emiss) }} \approx 490 \mathrm{~nm}$.

The reaction with sulfite. The ability to bind sulfite and form covalent N(5) adducts is a characteristic of flavoprotein oxidases (Massey et al., 1969; Massey and Hemmerich, 1980). It is generally assumed that in this class of flavoenzymes a positive (partial) charge near the flavin $\mathrm{N}(1)-\mathrm{C}(2)=0$ locus inductively promotes the process (Massey and Hemmerich, 1980). Both BCO and SCO form reversibly flavin $N(5)$-sulfite adducts (Fig. 2). The reversibility was assessed by dialysis or by measurement of the decay to reform oxidized enzyme upon filtration over Sephadex G-25. In contrast to the general case, however, the monophasic formation of the adduct has half-times of the order of minutes. To our knowledge, there are only three further cases of slow binding of sulfite to flavoenzymes, i.e.oxynitrilase, pig kid-

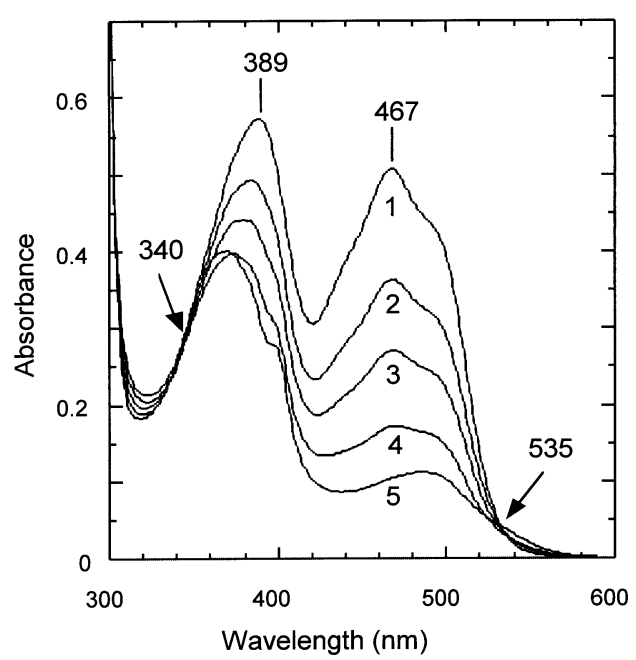

Fig. 3. Photoreduction of cholesterol oxidase from $S$. hygroscopicus. $52 \mu \mathrm{M}$ SCO in $0.05 \mathrm{M}$ potassium phosphate, $\mathrm{pH} 7.5$, at $25^{\circ} \mathrm{C}$ was made anaerobic and subsequently mixed with $15 \mathrm{mM}$ EDTA (spectrum 1 ). The further spectra were recorded after 10 (2), 20 (3), 40 (4), and 180 (5) min of irradiation. The arrows indicate the approximate isosbestic points of the conversion.

ney D-amino acid oxidase (Massey et al., 1969) and a mutant of L-lactate monooxygenase (Müh et al., 1994). Binding is a second-order process (data not shown) and from appropriate plots both $k_{\text {on }}$ and $k_{\text {off }}$ can be estimated (Table 2). The latter value coincides with that obtained by following the reappearance of the oxidized flavin spectrum upon removal of excess sulfite by gel filtration. While with $\mathrm{BCO}$ the adduct formation depends monophasically on sulfite concentration, the same process appears to be more complex with SCO as shown in Fig. 2. This is reflected in particular by the spectral changes in the 310-350-nm area, where an increase first occurs, the spectral changes having an isosbestic point at $340 \mathrm{~nm}$ up to $\approx 60 \%$ of the total conversion. The calculated spectrum of the intermediate is typical for flavin N(5)-sulfite adduct (Fig. 2) (Massey et al., 1969). Subsequently, the isosbestic conversion is lost concomitantly with a decrease of the absorbance. This leads to a species the calculated spectrum of which is still similar to the flavin $N(5)$-sulfite adducts (Massey et al., 1969), the difference of the latter being an $\approx 40 \%$ lower absorbance at $333 \mathrm{~nm}$. This behavior is not affected by the presence/absence of oxygen. From this it is unlikely that free reduced enzyme is present, the second species observed might thus reflect a conformational change and/or a secondary effect of sulfite. Both the binding constants and the kinetics of formation differ significantly for SCO and BCO (Table 2), and the high $K_{\mathrm{d}}$ value obtained for SCO accounts for the incomplete formation of adduct at the maximal sulfite concentration used (Fig. 2). Thus, while with many oxidases $K_{\mathrm{d}}$ values of the order of micromolar are not uncommon (Massey et al., $1969)$, in the present case they are in the millimolar range (Table 2).

Photoreduction and stabilization of the anionic flavin semiquinone. Both enzymes are photoreduced in the presence of EDTA at $25^{\circ} \mathrm{C}$ and $\mathrm{pH} 7.5$ with the formation of the red, anion semiquinone, typical of the flavoprotein oxidases class (Massey and Hemmerich, 1980). Two isosbestic points are observed at $340 \mathrm{~nm}$ and $535 \mathrm{~nm}$ during the formation of the semiquinone (Fig. 3 for the case of SCO). With both enzymes, the semiquinone intermediate is not formed completely during photoreduction. In the absence of a catalyst such as 5-deaza-riboflavin, the 
Table 3. Kinetic parameters of cholesterol oxidase using different substrates and different assays. The kinetic parameters were determined at $25^{\circ} \mathrm{C}$ and $\mathrm{pH} 7.5$. The three assays rely on the spectroscopical detection of product formation at $240 \mathrm{~nm}(\mathrm{~A})$, on the polarographic determination of the rate of oxygen consumption (B), and on the rate of $\mathrm{H}_{2} \mathrm{O}_{2}$ formation detected with $o$-dianisidine and horseradish peroxidase (C). The conditions are detailed in the Materials and Methods section. (a) $0.5 \mathrm{M}$ potassium phosphate, $1 \%$ Thesit, $1.25 \%$ isopropanol; (b) $0.1 \mathrm{M}$ potassium phosphate, $1 \%$ Triton X-100, $1.25 \%$ isopropanol.

\begin{tabular}{|c|c|c|c|c|c|c|}
\hline \multirow[t]{2}{*}{ Substrate } & \multirow[t]{2}{*}{ Type of assays } & \multirow[t]{2}{*}{ Conditions } & \multicolumn{2}{|l|}{$\mathrm{BCO}$} & \multicolumn{2}{|l|}{$\mathrm{SCO}$} \\
\hline & & & $K_{\mathrm{m}}$ & $k_{\text {cat }}$ & $K_{\mathrm{m}}$ & $k_{\text {cat }}$ \\
\hline & & & $\mathrm{mM}$ & $\mathrm{s}^{-1}$ & $\mathrm{mM}$ & $\mathrm{s}^{-1}$ \\
\hline \multirow{7}{*}{ Cholesterol } & 4-cholesten-3-one (A) & (a) & 0.14 & 67 & 0.2 & 11 \\
\hline & $\mathrm{O}_{2}(\mathrm{~B})$ & (a) & 0.11 & 56 & 0.25 & 9 \\
\hline & $\mathrm{O}_{2}(\mathrm{~B})$ & (a) however $10 \%$ isopropanol & 0.20 & 57 & 0.17 & 6 \\
\hline & $\mathrm{O}_{2}(\mathrm{~B})$ & (a) however $10 \%$ isopropanol & & & & \\
\hline & & and $50 \mathrm{mM} \mathrm{KP_{ \textrm {i } }}$ & 0.25 & 43 & 0.17 & 3 \\
\hline & 4-cholesten-3-one (A) & (b) & 0.07 & 48 & 0.8 & 63 \\
\hline & $\mathrm{H}_{2} \mathrm{O}_{2}(\mathrm{C})$ & (b) & 0.04 & 48 & 0.4 & 32 \\
\hline 5-Cholesten-3-one & 4-cholesten-3-one (A) & (a) & 0.27 & 278 & 1.52 & 332 \\
\hline \multirow[t]{2}{*}{ trans-Dehydroandrosterone } & 4-cholesten-3-one (A) & (b) & 1.2 & 0.8 & 0.3 & 8.2 \\
\hline & $\mathrm{H}_{2} \mathrm{O}_{2}(\mathrm{C})$ & (b) & 0.9 & 1.0 & 0.2 & 6.0 \\
\hline \multirow[t]{2}{*}{ Pregnenolone } & 4-cholesten-3-one (A) & (b) & 0.4 & 21 & 0.2 & 24 \\
\hline & $\mathrm{H}_{2} \mathrm{O}_{2}(\mathrm{C})$ & (b) & 0.2 & 35 & 0.2 & 21 \\
\hline Cholestanol & $\mathrm{H}_{2} \mathrm{O}_{2}(\mathrm{C})$ & (b) & 0.2 & 40 & 0.7 & 37 \\
\hline trans-Androsterone & $\mathrm{H}_{2} \mathrm{O}_{2}(\mathrm{C})$ & (b) & 0.8 & 0.8 & 0.5 & 7 \\
\hline
\end{tabular}

process is quite slow $\left(t_{1 / 2} \approx 15 \mathrm{~min}^{-1}\right.$ for both CO enzymes in $0.1 \mathrm{M}$ potassium phosphate) and this velocity is inversely dependent on the ionic strength of the buffer $\left(t_{1 / 2} \approx 2 \mathrm{~min}^{-1}\right.$ for both $\mathrm{CO}$ enzymes in $0.05 \mathrm{M}$ potassium phosphate). The spectrum of the fully reduced species is not obtained even after $24 \mathrm{~h}$ of irradiation. This phenomenon has also been described for glycolate oxidase, lactate and glucose oxidase (Macheroux et al., 1991). On admission of oxygen, essentially complete reoxidation is observed. These results are compatible with a kinetic stabilization of the (red) anionic flavin semiquinone as observed also with other flavoprotein oxidases (Massey and Hemmerich, 1980).

Determination of the redox potentials. The method described by Massey (1991) has been used for determining the midpoint redox potentials for the transfer of electrons to the flavin at $25^{\circ} \mathrm{C}$ and $\mathrm{pH}$ 7.5. For both enzymes, the separation of the two redox potentials was determined from the maximal percentage of the semiquinone reached during the reduction using benzyl viologen $\left(E_{\mathrm{m}}=-359 \mathrm{mV}\right)$ as dye. The midpoint potential appears to be more positive in the case of $\mathrm{BCO}$, by about $100 \mathrm{mV}$ as compared to that of SCO (Table 4). The redox potential for the transfer of each single electron has been determined using various dyes having different redox potential. In Fig. 4, the reduction of SCO at pH 7.5 in the presence of $15 \mu \mathrm{M}$ safranin T as mediator is shown. The absorbance changes at $520 \mathrm{~nm}$ (corresponding to the wavelength of maximal change during the conversion from oxidized to reduced form of the dye and to an isosbestic point for the oxidized-semiquinone conversion of the enzyme), $410 \mathrm{~nm}$ (an isosbestic point for the dye), and $366 \mathrm{~nm}$ (an absorption maximum for the semiquinone form of SCO) are shown in Fig. 4 A. From these data and from the known absorption coefficients of the oxidized, semiquinone, and reduced forms of SCO (Table 1) the plot of $\log (\mathrm{seq} / \mathrm{red})$ for $\mathrm{SCO}$ versus $\log$ (ox/red) for the dye was plotted according to Minnaert (1965) (Fig. 4B). From this, the $\Delta E_{\mathrm{m}}$ between the dye and the enzyme was calculated. The redox potential for each single electron transfer is markedly more negative for SCO from that for BCO (Table 4).

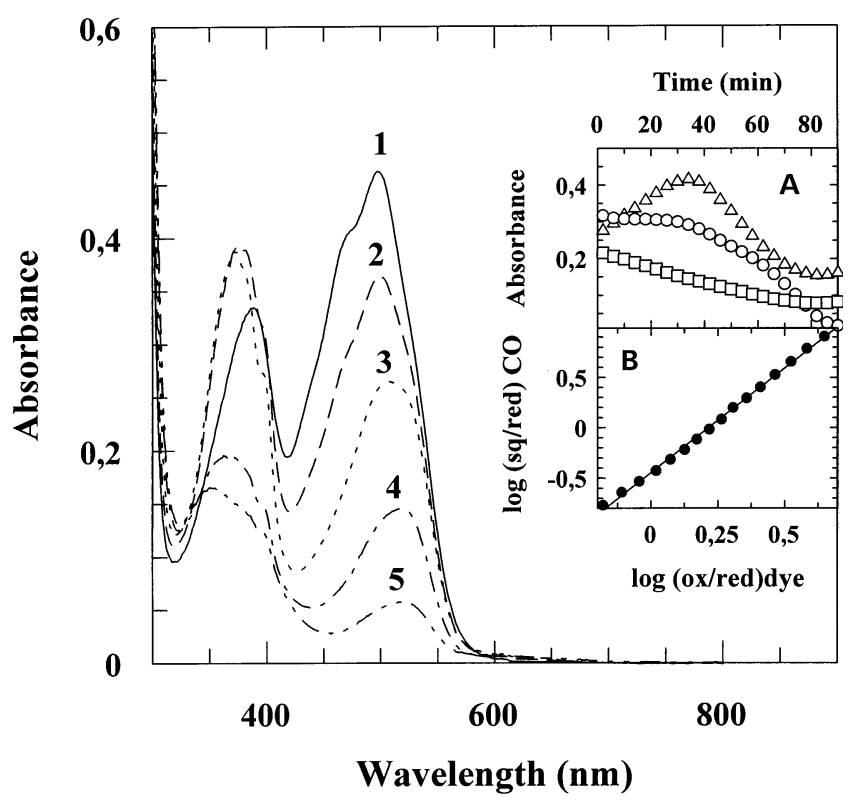

Fig. 4. Determination of the redox potential of cholesterol oxidase from S. hygroscopicus. Selected spectra obtained during the course of the anaerobic reduction of $31.2 \mu \mathrm{M} \mathrm{SCO}$ (1) in $100 \mathrm{mM}$ potassium phosphate, $\mathrm{pH} 7.5$, in the presence of $200 \mu \mathrm{M}$ xanthine and $15 \mu \mathrm{M}$ safranin $\mathrm{T}\left(E_{\mathrm{m}}=-276 \mathrm{mV}\right)$. Selected curves are shown that were obtained upon addition of $30 \mathrm{nM}$ xanthine oxidase. (2) after 24; (3) 48; (4) 72; and (5) 84 min after addition of xanthine oxidase. (A) Time-dependent absorption changes observed at $520(\bigcirc), 410(\square)$ and $366 \mathrm{~nm}(\triangle)$. (B) Nernst plot according to Minnaert (1965) $(n=2.074)$.

Catalytic properties. The cholesterol-oxidizing activity of the two purified $\mathrm{CO}$ enzymes is optimal between $\mathrm{pH} 6.0$ and $\mathrm{pH} 8.0$ and decreases sharply below $\mathrm{pH}$ 6.0. This is in agreement with data previously reported for $\mathrm{CO}$ from Streptomyces violascens 
Table 4. Redox potentials of cholesterol oxidase from B. sterolicum and S. hygroscopicus. The redox potentials were determined spectroscopically using the xanthine and xanthine oxidase system (Massey, 1991) in $100 \mathrm{mM}$ potassium phosphate, $\mathrm{pH} 7.5$, at $15^{\circ} \mathrm{C}$ employing as redox standard cresyl violet and safranin $\mathrm{T}\left(E_{\mathrm{m}}-176 \mathrm{mV}\right.$ and $-276 \mathrm{mV}$, respectively) for $\mathrm{SCO}$ and indigo disulfonate and cresyl violet $\left(E_{\mathrm{m}}-74 \mathrm{mV}\right.$ and $-176 \mathrm{mV}$, respectively) for $\mathrm{BCO}$.

\begin{tabular}{lllll}
\hline Enzyme & $\begin{array}{l}\text { Maximal amount } \\
\text { of semiquinone formed }\end{array}$ & $\Delta E$ & $E_{1}^{\circ \prime}\left(\mathrm{EFl}_{\text {ox }} / \mathrm{EFl}^{-}\right)$ & $E_{2}^{\circ \prime}\left(\mathrm{EFl}^{-} / \mathrm{EFl}_{\mathrm{red}}\right)$ \\
\hline & $\%$ & $\mathrm{mV}$ & & \\
\cline { 2 - 3 } & $\approx 65$ & $-67 \pm 15$ & $-74.1 \pm 0.7$ & $-127.3 \pm 4.3$ \\
BCO & $\approx 71$ & $-81 \pm 14$ & $-179.1 \pm 18$ & $-255.3 \pm 2.5$ \\
\hline
\end{tabular}

Scheme 1. Reactions catalyzed by cholesterol oxidase and structures of species involved. Note that 5 -cholesten-3-one is the assumed intermediate. Its conversion to the final product, 4-cholesten-3-one, is faster than its formation.

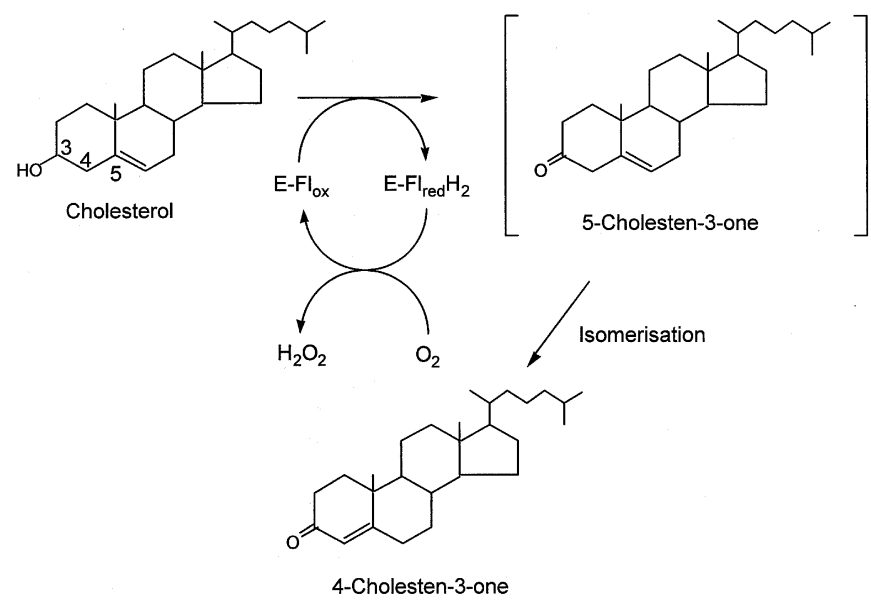

(Tomioka et al., 1976), from Streptoverticillum cholesterolicum (Inouye et al., 1982), and from Arthrobacter simplex (Lui, 1988). In the presence of catalase, the rate of oxygen consumption is approximately halved, which is compatible with hydrogen peroxide production. The catalytic parameters are reported in Table 3. In the case of $\mathrm{BCO}$, there is a good correlation between the results of assays (A) and (B) or (B) and (C), with SCO. However, with assay $(C)$ only $\approx 50 \%$ the value of assay (A) was found when cholesterol was used as substrate. No reason is apparent at present for this discrepancy. Comparison of the rates of turnover with cholesterol, with those of the rearrangement of 5-cholesten-3-one to 4-cholesten-3-one indicates that with both $\mathrm{BCO}$ and SCO the rate-limiting step of the overall reaction is not the rearrangement (Table 3 ). The ratios between the isomerization and oxidation are $\approx 4$ and $\approx 30$ for $\mathrm{BCO}$ and $\mathrm{SCO}$, respectively. With CO from Nocardia, a ratio of $\approx 2$ was measured for the two reactions (Smith and Brooks, 1977). In the case of SCO, in which FAD is not covalently bound, addition of FAD does not increase the maximal activity, in agreement with the observation of a very tight binding of the cofactor (Wels, 1997). 2-Mercaptoethanol also does not affect on the activity. Both the concentration of solvent and of detergent, required for solubilization of substrates, affect to a different extent the activity of these enzymes (Table 3).

Substrate specificity. The influence of the substrate $\mathrm{C} 17$ chain upon $\mathrm{CO}$ activity is an important topic in the context of $\mathrm{CO}$ catalysis (Uwajima et al., 1974; Tomioka et al., 1976; Kamei et al., 1978; Smith and Brooks, 1977; Fukuyama and Miyake, 1979; Inouye et al., 1982; Lui, 1988). In spite of this, only in the case of CO from Nocardia the kinetic parameters $k_{\text {cat }}$ and $K_{\mathrm{m}}$ were estimated in this context (Smith and Brooks, 1977). The relevant parameters for $\mathrm{SCO}$ and $\mathrm{BCO}$ are listed in Table 3. With both enzymes, the data obtained using test (A) and (C) agree reasonably well, indicating that rearrangement is not rate limiting also with steroids devoid of the $\mathrm{C} 17$ side chain (Scheme 1). On the other hand, a decreasing length of the $\mathrm{C} 17$ chain affects turnover negatively. This is particularly evident with $\mathrm{BCO}$, where the oxidation rate with trans-dehydroandrosterone is only $2 \%$ of that found with cholesterol, the $K_{\mathrm{m}}$ also being $\approx$ tenfold higher. With CO from Streptoverticillum cholesterolicum (Inouye et al., 1982) and Streptomyces violascens (Kamei et al., 1978), a high oxidase activity has been reported for steroids with a saturated B-ring. However, activity comparisons were not based on the determination of kinetic parameters, casting some doubts on the conclusions. As shown in Table 3 for the case of cholestanol and trans-androsterone (a substrate-product couple, the structures of which correspond to those of cholesterol and trans-dehydroandrosterone, but without the $\Delta^{5}$ double bond), BCO and SCO are not significantly affected in their turnover number and affinity for the substrate by the absence of the double bond in the steroid molecule.

Effect of detergent, alcohol, and phosphate upon cholesterol oxidase activity. As the presence of detergent and alcohol is required for solubilization of substrates of $\mathrm{CO}$, the effect of Thesit, isopropanol, and phosphate ions upon activity was investigated. BCO activity is enhanced by high concentrations of phosphate ions and decreased as a function of detergent concentration. No effect upon activity is observed when isopropanol is raised from $0.4 \%$ to $4.4 \%$. On the other hand, SCO is dramatically sensitive both to detergent and isopropanol, whereas a minor effect is observed with phosphate. The effect of isopropanol upon SCO activity is more pronounced. Comparing the kinetic parameters determined in $1.25 \%$ and $10 \%$ alcohol, $k_{\text {cat }}$ at high concentration of alcohol is $65 \%$ of that estimated at low concentration. Since with SCO a strong inactivation was observed at increasing Thesit concentrations (at $2.3 \%$ Thesit the activity was $\approx 15 \%$ compared to that at $0.3 \%$ Thesit), we have studied the effects of Triton X-100. With this detergent, SCO activity is doubled compared to that in the presence of Thesit and reaches a maximum at around $0.7 \%$ detergent concentration, subsequently decreasing at higher concentrations (data not shown).

\section{CONCLUSIONS}

The results reported in the present work indicate that $\mathrm{CO}$ from Streptomyces hygroscopicus and the recombinant enzyme from Brevibacterium sterolicum share some of the typical prop- 
erties of the class of flavoprotein oxidase, namely the ability to form a reversible flavin-adduct with sulfite and the (partial) thermodynamic stabilization of the red anion semiquinone upon photoreduction (Massey and Hemmerich, 1980). The reactivity of the two enzymes towards sulfite is slow and appears to be very different. While with $\mathrm{BCO}$ the $K_{\mathrm{d}}$ is in the usual range observed with flavoprotein oxidases $(\approx 0.14 \mathrm{mM})$, in the case of SCO this value is $170-400$ times higher. The major contribution to this difference is from the rate of formation of the adduct, which is $\approx 50$ times faster with BCO. Thus, in the two enzymes the reactivity of the $\mathrm{N}(5)$ position of FAD appears to be differently modulated by the protein environment at the flavin site. This is also evident by comparing the values of the midpoint redox potential. With SCO, this value $(-217 \mathrm{mV})$ is close to that of free FAD ( $-207 \mathrm{mV}$ FAD), and similar to other flavoenzymes belonging to the oxidase family (Stankovich, 1991). In the case of BCO, however, and since the midpoint redox potential for the electrons transfer to the flavin is $\approx 100 \mathrm{mV}$ more positive compared to that of SCO the modulation exerted by the apoprotein counterpart upon the flavin must be much stronger confirming, even for these two COs, the correlation between the dissociation constant of the flavin sulfite complexes and their corresponding redox potentials (Müller and Massey, 1969). This is probably what is reflected also by the very different spectral properties of the same flavin chromophore at the oxidized, semiquinone, and fully reduced states bound either to SCO or BCO. It should also be pointed out that BCO used in this work contains covalently linked flavin, while the FAD in SCO is not covalently linked. The upcoming three-dimensional structure of the present BCO (Croteau and Vrielink, 1996), in comparison with the known structure of a $\mathrm{CO}$ from a different Brevibacterium sterolicum strain (which contains non-covalently linked FAD) (Vrielink et al., 1991), is expected to help clarify some of these issues.

As far as the catalytic properties of cholesterol oxidase are concerned, with both enzymes the rearrangement of 5-cholesten3-one to 4-cholesten-3-one does not seem to be the rate-limiting step of the overall reaction, at least under the conditions used in this study. With both enzymes, the presence of a double bond in the B-ring of the substrate steroid backbone is not required for activity, indicating that the rearrangement and redox steps are carried out by two different and unrelated chemistries. A detailed study of the kinetic mechanism of BCO and SCO is currently underway. Finally, the similarities in catalytic properties of SCO and BCO paired with the differences in their primary structures (Wels, 1997) and overall biochemical behavior reported here suggests a case of converging evolution.

This work was supported by grants from EEC Network FLAPS (Flavoprotein Dynamics, Catalysis and Cellular Biology) to Dr S. Ghisla, Konstanz, Germany and to Dr B. Curti, Milano, Italy. We thank Dr Stefano Campaner for developing a gel staining procedure for assessing $\mathrm{CO}$ activity.

\section{REFERENCES}

Corbin, D. R., Greenplate, J. T., Wong, E. Y. \& Purcell, J. P. (1994) Cloning of an insecticidal cholesterol oxidase gene and its expression in bacteria and plant protoplasts, Appl. Environ. Microbiol. 60, 4239-4244.

Croteau, N. \& Vrielink, A. (1996) Crystallization and preliminary Xray analysis of cholesterol oxidase from Brevibacterium sterolicum containing covalently bound FAD, J. Struct. Biol. 116, 317-319.

Fukuyama, M. \& Miyake, Y. (1979) Purification and some properties of cholesterol oxidase from Schizophyllum commune with covalently bound flavin, J. Biochem. (Tokyo) 85, 1183-1193.
Ghisla, S., Massey, V., Lhoste, J. M. \& Mayhew, S. G. (1974) Fluorescence and optical characteristics of reduced flavins and flavoproteins, Biochemistry 13, 589-597.

Ghoshroy, K. B., Zhu, W. \& Sampson, N. S. (1997) Investigation of membrane disruption in the reaction catalyzed by cholesterol oxidase, Biochemistry 36, 6133-6140.

Inouye, Y., Taguchi, K., Fujii, A., Ishimaru, K., Nakamura, S. \& Nomi, R. (1982) Purification and characterization of extracellular 3- $\beta$-hydroxysteroid oxidase produced by Streptoverticillum cholesterolicum, Chem. Pharm. Bull. 30, 951-958.

Ishizaki, T., Hirayama, N., Shinkawa, H., Nimi, O. \& Murooka, Y. (1989) Nucleotide sequence of the gene for cholesterol oxidase from a Streptomyces sp., J. Bacteriol. 171, 596-601.

Johnson, T. L. \& Somkuti, G. A. (1991) Isolation of cholesterol oxidase from Rhodococcus equi ATCC 33706, Biotechnol. Appl. Biochem. 13, 196-204.

Kamei, T., Takiguchi, Y., Suzuki, H., Matsuzaki, M. \& Nakamura, S. (1978) Purification of 3- $\beta$-hydroxysteroid oxidase of Streptomyces violascens origin by affinity chromatography on cholesterol, Chem. Pharm. Bull. 26, 2799-2804.

Laemmli, U. K. (1970) Cleavage of structural proteins during the assembly of the head of bacteriophage T4, Nature 227, 680-685.

Lee, S., Rhee, H., Tae, W., Shin, J. \& Park, B. (1989) Purification and characterization of cholesterol oxidase form Pseudomonas sp. and taxonomic study of the strain, Appl. Microbiol. Biotechnol. 31, 542546.

Li, J., Vrielink, A., Brick, P. \& Blow, D. M. (1993) Crystal structure of cholesterol oxidase complexed with a steroid substrate: implications for flavin adenine dinucleotide dependent alcohol oxidases, Biochemistry 32, 11507-11515.

Lui, W. H. (1988) Purification and some properties of cholesterol oxidases produced by an inducible and a constitutive mutant of Arthrobacter simplex, Agric. Biol. Chem. 52, 413-418.

Macheroux, P., Massey, V. \& Thiele, D. J. (1991) Expression of spinach glycolate oxidase in Saccharomyces cerevisiae: purification and characterization, Biochemistry 30, 4612-4619.

Massey, V. \& Ganther, H. (1965) On the interpretation of the absorption spectra of flavoproteins with special reference to D-amino acid oxidase, Biochemistry 4, 1161-1173.

Massey, V., Müller, F., Feldberg, R., Schuman, M., Sullivan, P. A., Howell, L. G., Mayhew, S. G., Matthews, R. G. \& Foust, G. P. (1969) The reactivity of flavoproteins with sulphite, J. Biol. Chem. 244, 3999-4006.

Massey, V., Stankovich, M. \& Hemmerich, P. (1978) Light-mediated reduction of flavoproteins with flavins as catalysts, Biochemistry 17, $1-8$.

Massey, V. \& Hemmerich, P. (1980) Active-site probes of flavoproteins, Biochem. Soc. Trans. 8, 246-255.

Massey, V. (1991) A simple method for the determination of redox potentials, in Flavins and flavoproteins 1990 (Curti, B., Ronchi, S. \& Zanetti, G., eds) pp. 59-66, Walter de Gruyter \& Co., Berlin.

Minnaert, K. (1965) Measurement of the equilibrium constant of the reaction between cytochrome $c$ and cytochrome a,Biochim. Biophys. Acta 110, 42-56.

Müh, U., Massey, V. \& Williams, C. W. Jr (1994) Lactate monooxygenase. I. Expression of the mycobacterial gene in Escherichia coli and site-directed mutagenesis of lysine 266, J. Biol. Chem. 269, 79827988.

Müller, F. \& Massey, V. (1969) Flavin-sulphite complexes and their structures, J. Biol. Chem. 244, 4007-4016.

Otha, T., Fujishiro, K., Yamaguchi, K., Tamura, Y., Aisaka, K., Uwajima, T. \& Hasegawa, M. (1991) Sequence of gene $c h o B$ encoding cholesterol oxidase of Brevibacterium sterolicum: comparison with choA of Streptomyces sp. SA-COO, Gene (Amst.) 103, 93-96.

Purcell, J. P., Greenplate, J. T., Jennings, M. G., Ryerse, J. S., Pershing, J. C., Sims, S. R., Prinsen, M. J., Corbin, D. R., Tran, M., Sammons, R. D. \& Stonard, R. J. (1993) Cholesterol oxidase: a potent insecticidal protein active against boll weevil larvae, Biochem. Biophys. Res. Commun. 196, 1406-1413.

Smith, A. G. \& Brooks, C. J. W. (1975) The mechanism of the isomerisation of cholest-5-en-3-one to cholest-4-en-3-one by cholesterol oxidase, Biochem. Soc. Trans. 3, 675-677.

Smith, A. G. \& Brooks, C. J. W. (1977) The substrate specificity and stereochemistry, reversibility and inhibition of the 3-oxo steroid $\Delta^{4}$ - 
$\Delta^{5}$-isomerase component of cholesterol oxidase, Biochem. J. 167 , 121-129.

Stankovich, M. T. (1991) Redox properties of flavins and flavoproteins, in Chemistry and biochemistry of flavoenzymes (Müller, F., ed.) pp. 401-425, CRC Press, Boca Raton, USA.

Tomioka, H., Kagawa, M. \& Nakamura, S. (1976) Some enzymatic properties of 3- $\beta$-hydroxysteroid oxidase produced by Streptomyces violascens, J. Biochem. (Tokyo) 79, 903-915.

Uwajima, T., Yagi, H., Nakamura, S. \& Terada, O. (1973) Isolation and crystallisation of extracellular 3- $\beta$-hydroxysteroid oxidase of Brevibacterium sterolicum nov. sp., Agric. Biol. Chem. 37, 2345-2350.
Uwajima, T., Yagi, H. \& Terada, O. (1974) Properties of crystalline 3- $\beta$-hydroxysteroid oxidase of Brevibacterium sterolicum, Agric. Biol. Chem. 38, 1149-1156.

Vrielink, A., Lloyd, L. F. \& Blow, D. M. (1991) Crystal structure of cholesterol oxidase of Brevibacterium sterolicum refined at $1.8 \AA$ resolution, J. Mol. Biol. 219, 533-554.

Wels, G. (1997) PhD thesis, University of Konstanz.

Whitby, L. G. (1953) A new method for preparing flavin-adenine dinucleotide, Biochem. J. 54, 437-442. 